\title{
PENGARUH POLA ASUH DEMOKRATIF TERHADAP PERKEMBANGAN SOSIAL REMAJA
}

\author{
Cintia Fajri Utami ${ }^{1}$, Poppy Fitriyani ${ }^{2}$ \\ ${ }^{1}$ Fakultas Ilmu Keperawatan Universitas Indonesia. \\ ${ }^{2}$ Departemen Keperawatan Komunitas Fakultas Ilmu Keperawatan Universitas Indonesia. Gedung RIK UI, \\ Depok, Jawa Barat - 16424 \\ poppy@ui.ac.id
}

\begin{abstract}
Abstrak
Tahapan usia remaja identik dengan pembentukan identitas diri pada tugas perkembangan sosial dimana keluarga sebagai lingkungan sosial utama bagi remaja. Penelitian ini bertujuan untuk mengetahui hubungan antara pola asuh orang tua dengan perkembangan sosial remaja di SMP Taruna Bhakti Depok menggunakan desain deskriptif korelatif. Penelitian ini menggunakan 293 sampel yang terdiri dari kelas VII dan VIII SMP dengan teknik pemilihan sampel proportioned stratified random sampling. Instrumen Pola Asuh yang digunakan diadaptasi dari kuesioner penelitian Mashoedi serta instrumen Perkembangan Sosial yang disusun oleh peneliti. Hasil analisis menunjukkan bahwa terdapat hubungan antara pola asuh orang tua dengan perkembangan sosial remaja $(\mathrm{p}=0,000)$ dengan kesimpulan remaja dengan pola asuh demokratif berpeluang memiliki perkembangan sosial sesuai dibandingkan dengan tipe pola asuh lainnya. Oleh karena itu, diharapkan agar mahasiswa, pelayanan dan profesi keperawatan dapat bekerja sama dengan instansi terkait dalam memberikan edukasi dan motivasi kepada orang tua dalam meningkatkan peran orang tua terhadap perkembangan sosial remaja.
\end{abstract}

Kata kunci: Remaja, pola asuh, prkembangan sosial

\begin{abstract}
Influence of Authoritative Parenting Pattern on Adolencence Social Development. The stage of adolescence is identical with the self-identity building in the task of social development whereas family plays role as the main social community for them. This research aims to understand the relationship between parenting pattern and the social development of adolescents in SMP Taruna Bhakti Depok by using correlative descriptive design. This study uses 293 research samples consisting of class VII and VIII SMP with sample selection technique proportioned stratified random sampling. The parenting pattern instruments are adapted from Mahshodie's while the research and adolescent social development questionnaire compiled by researcher. The result of the analysis shows that there is a relationship between parenting pattern and adolescent social development $(p=0,000)$ with the conclusion that adolescents with democratized parenting pattern tend to have the appropriate social development category compared with other parenting types. Therefore, it is expected that students, services and nursing professions can work together with school agencies to be able to provide education and advocacy to parents related to the role of parenting to the social development of adolescents.
\end{abstract}

Keywords: Adolescent, parenting style, social development

\section{Pendahuluan}

Remaja merupakan periode transisi antara masa anak-anak dengan dewasa. Tiga tahapan pada pertumbuhan dan perkembangan remaja, yaitu remaja awal (early adolescence) (11-14 tahun), remaja tengah (middle adolescence) (15-17 tahun), dan remaja akhir (late adolescence) (18-20 tahun) (Hockenberry, Marilyn, \& Wilson, 2015). Pada masa pencarian identitas diri ini remaja akan mencoba berbagai peran dalam berinteraksi dengan lingkungan sosial (Santrock, 2011). Sesuai dengan tugas perkembangan sosial remaja yaitu mampu menjalankan fungsi sosial dan membentuk peran sosial sesuai identitas diri dalam beradaptasi dengan nilai dan norma lingkungan (Christensen, 2011 dan Nurhayati, 2014). Menurut Erikson, remaja berada pada tahapan identity vs role confusion (12-19 tahun). Remaja akan berusaha mengidentifikasi dan menentukan kemampuan atau keterampilan diri dengan tujuan untuk menentukan peran dan masa depannya.

Menurut Desmita (2010), terdapat enam aspek penting dalam perkembangan sosial remaja, yaitu perkembangan 
individu dan pembentukan identitas diri; hubungan dengan orang tua; hubungan dengan teman; perkembangan seksualitas; proaktivitas; dan kemampuan dalam beradaptasi. Remaja yang berhasil menentukan identitas dan peran diri di lingkungan sosialnya dapat tumbuh menjadi individu yang mampu mengatasi konflik diri maupun lingkungan dengan percaya diri yang tinggi (Kyle \& Carman, 2013). Sebaliknya, remaja yang gagal menemukan identitas diri akan mengalami kebingungan peran yang ditampilkan dengan sikap menarik diri dari pergaulan atau bahkan cenderung mengikuti identitas kelompoknya (peer group) akibat kebingungan peran (Kwon, Kim, \& Sheridan, 2012 dan Hockenberry, Marilyn, \& Wilson, 2015).

Fenomena permasalahan sosial pada remaja pada saat sekarang ini diantaranya adalah perilaku merokok dibawah usia 19 tahun (Simons-Morton \& Farhat, 2010; Nurmanah, 2012; dan Hendrian, 2017); perilaku bullying dan penolakan sosial (social rejection) (Crone \& Dahl, 2012 dan Sebastian, 2015); meningkatnya kasus tawuran antar pelajar (Malau, 2017); dan penggunaan media sosial yang berlebihan (Radovic, Gmelin, Stein, \& Miller, 2016). Sekitar $40 \%$ remaja menyadari bahwa penggunaan media sosial yang berlebihan dapat membahayakan diri mereka, misalnya terlalu berisiko untuk memberikan informasi pribadi, cyberbullying, pergaulan yang melampaui batas nilai dan norma, serta hal negatif lainnya (Madden, et al., 2013). Kondisi ini berpotensi meningkatkan risiko depresi pada remaja yang tidak menggunakan media sosial sebagaimana mestinya (Daine, Hawton, Singaravelu, Stewart, Simkin, \& Montgomery, 2013 dan Radovic, Gmelin, Stein, \& Miller, 2016). Fenomena ini didukung oleh Profil Kesehatan Kota Depok (2015) yang mencatat sekitar 30 kasus depresi terjadi pada laki-laki dan 35 kasus baru pada perempuan, dengan total kasus baru dan lama sekitar 146 kasus (Dinas Kesehatan
Kota Depok, 2016). Sekitar 91\% remaja yang menjadi korban bullying secara langsung teridentifikasi mengalami gejala depresi dan sekitar $2,5 \%$ remaja mengalami depresi akibat bullying secara tidak langsung, seperti melalui pesan singkat ataupun media sosial (Mitchell, Ybarra, \& Finkelhor, 2007 dalam Ubertini, 2010). Selain itu, Ubertini (2010) menyimpulkan bahwa remaja yang menjadi korban bullying serta permasalahan sosial lainnya memiliki kepercayaan diri yang lebih rendah dibandingkan dengan remaja normal lainnya.

Keluarga merupakan lingkungan sosial pertama dan sangat mempengaruhi perkembangan sosial remaja. Pola asuh merupakan proses peran orang tua dalam memberikan arahan kepada anak mengenai perilaku, kepercayaan, moral, dan nilainilai lainnya dalam keluarga dengan tujuan untuk dapat bersosialisasi dan berkontribusi dalam lingkungan sosial (Bowden, 2010 dan Ball, 2012). Pola asuh terbagi menjadi empat tipe pola asuh, yaitu demokratif, permisif, otoriter, dan neglectful yang dikategorikan berdasarkan dimensi penerimaan dan dimensi pengendalian (Baumrind, 2005 dan Boyd \& Bee, 2006).

Penelitian Pahur (2008) dan Abubakar, Van de Vijver, Suryani, Handayani, \& Pandia (2015) pada remaja usia remaja disimpulkan bahwa remaja dengan pola asuh demokratif memiliki kemampuan interaksi sosial yang lebih baik dibandingkan remaja dengan pola asuh lainnya. Pola asuh demokratif dicirikan dengan indikator sikap ramah dan kontrol orang tua yang tinggi (Ball, 2012). Orang tua melakukan kontrol yang tinggi pada anak namun bersikap terbuka dengan pendapat dan pandangan anak. Tuntutan dan batasan yang ditetapkan jelas dan mempertimbangkan kemampuan anak (Harris-Mckoy \& Cui, 2013). Lain halnya dengan pola asuh neglectful atau pengabaian yang menampilkan perilaku orang tua yang cenderung mengabaikan 
anak sehingga orang tua tidak memberikan tuntutan dan jarang berinteraksi dengan anak (Craig \& Dunn, 2007).

Orang tua dengan pola asuh ini jarang memerhatikan kebutuhan anak terutama memberikan waktunya untuk berkasih sayang dengan anak. Orang tua akan menyerahkan segala keputusan terkait anak sepenuhnya kepada anak (Ball, 2012). Oleh karena itu, muncullah pertanyaan apakah pola asuh orang tua berhubungan dengan perkembangan sosial remaja di salah satu sekolah Kota Depok, yaitu SMP Taruna Bhakti Depok.

\section{Metode}

Penelitian ini menggunakan desain deskriptif korelatif dengan studi pendekatan cross sectional. Jumlah sampel penelitian ini adalah 293 sampel yang terdiri dari siswa kelas VII dan VIII di SMP Taruna Bhakti Depok. Teknik pemilihan sampel yang digunakan adalah proportioned stratified random sampling yang disesuaikan dengan proporsi masing- masing kelas. Alat pengumpulan data yang digunakan pada penelitian ini berupa kuesioner yang terdiri dari karakteristik responden (meliputi usia, jenis kelamin, tingkat pendidikan orang tua, status pekerjaan orang tua); kuesioner perkembangan sosial remaja yang disusun oleh peneliti berjumlah 18 pertanyaan; dan kuesioner pola asuh orang tua yang diadaptasi dari kuesioner penelitian Mashoedi (2003) dalam Nurhafid (2013) berjumlah 35 pertanyaan. Proses pengolahan data dilakukan dengan melakukan proses coding data menggunakan program statistik komputer yaitu SPSS. Uji proporsi dilakukan sebagai analisis univariat pada seluruh karakteristik responden dan orang tua serta kedua variabel penelitian. Selain itu, Uji chisquare pada analisis bivariat dilakukan untuk melihat hubungan antara pola asuh orang tua (variabel independen) dengan perkembangan sosial remaja (variabel dependen).

\section{Hasil}

Tabel 1.

Pola Asuh Orang Tua Responden $(n=293)$

\begin{tabular}{lcc}
\hline \multicolumn{1}{c}{ Pola Asuh Orang Tua } & f & $\%$ \\
\hline Demokratif & 71 & 24,2 \\
Permisif & 62 & 21,2 \\
Otoriter & 72 & 24,6 \\
Neglectful & 88 & 30,0 \\
\hline
\end{tabular}

Tabel 2.

Perkembangan Sosial Remaja $(n=293)$

\begin{tabular}{lcc}
\hline \multicolumn{1}{c}{ Perkembangan Sosial Remaja } & Frekuensi & Persentase (\%) \\
\hline Sesuai & 161 & 54,9 \\
Tidak Sesuai & 131 & 45,1 \\
\hline
\end{tabular}

Tabel 3.

Hubungan Pola Asuh Orang Tua dengan Perkembangan Sosial Remaja ( $\mathrm{n}=293)$

\begin{tabular}{|c|c|c|c|c|c|c|}
\hline \multirow{3}{*}{ Pola Asuh Orang Tua } & \multicolumn{4}{|c|}{ Perkembangan Sosial Remaja } & \multirow{3}{*}{ Total } & \multirow{3}{*}{$P$ value } \\
\hline & \multicolumn{2}{|c|}{ Sesuai } & \multicolumn{2}{|c|}{ Tidak Sesuai } & & \\
\hline & $\mathrm{f}$ & $\%$ & $f$ & $\%$ & & \\
\hline Demokratif & 53 & 74,6 & 18 & 25,4 & 71 & \\
\hline Permisif & 27 & 43,5 & 35 & 56,5 & 62 & 0,000 \\
\hline Otoriter & 49 & 68,1 & 23 & 31,9 & 72 & \\
\hline
\end{tabular}




\begin{abstract}
Neglectful
Hasil analisis hubungan antara

kedua variabel tersebut dapat disimpulkan bahwa hubungan antara pola asuh orang tua dengan perkembangan sosial remaja (nilai $\mathrm{p}<0,005$ ), dimana hampir sebagian besar remaja dengan pola asuh demokratif memiliki perkembangan sosial kategori sesuai.
\end{abstract}

\section{Pembahasan}

Pada penelitian ini didapatkan data bahwa proporsi masing-masing tipe pola asuh tidak berbeda jauh, namun jumlah pola asuh orang tua responden terbanyak adalah pola asuh neglectful. Pola asuh neglectful dicirikan dengan perilaku orang tua dengan dimensi penerimaan dan pengendalian yang rendah. Menurut Craig \& Dunn (2007) dan Ball (2012) orang tua dengan pola asuh neglectful cenderung menyerahkan seluruh keputusan atas kepentingan anak sepenuhnya kepada anak. Sehingga, anak dengan pola asuh ini lebih beresiko mengalami permasalahan sosial terutama pada masa remaja, contohnya menampilkan sikap agresi, kurang disiplin, kurang percaya diri, serta impulsif dan mengarah kepada kenakalan remaja seperti merokok, tawuran, dan lainnya (Milevsky, Schlechter, Netter, \& Keehn, 2008 dan Rosli, 2014).

Berdasarkan hasil penelitian ini didapatkan data bahwa lebih dari separuh responden memiliki perkembangan sosial pada kategori sesuai berdasarkan enam dimensi perkembangan sosial, diantaranya perkembangan dan pembentukan identitas diri, hubungan dengan orang tua, hubungan dengan teman, perkembangan seksualitas, proaktivitas, serta kemampuan dalam beradaptasi (Desmita, 2010). Pada penelitian ini, peneliti juga menggunakan dimensi perkembangan dan pembentukan identitas diri serta hubungan dengan teman. Pada dimensi perkembangan dan pembentukan identitas diri berfokus kepada bagaimana sikap remaja dalam mencari dan menentukan identitas diri. Pada poin ini peneliti menggunakan item
$56 \quad 63,6 \quad 88$

pertanyaan mengenai interaksi responden dengan teman serta bagaimana sikap responden dalam menentukan keputusan dan keinginannya. Sedangkan pada dimensi hubungan dengan teman berfokus kepada bagaimana sikap responden dalam mempertahankan hubungan dengan teman serta menghormati hak dan perasaan teman. Selain itu, terdapat dimensi perkembangan proaktivitas yang berfokus kepada rasa ingin tahu responden serta kepercayaan terhadap diri sendiri.

Pada analisis bivariat, didapatkan data bahwa sebagian besar responden dengan pola asuh demokratif memiliki perkembangan sosial remaja yang sesuai. Berbeda halnya pada responden dengan tipe pola asuh neglectful yang memiliki perkembangan sosial remaja yang tidak sesuai. Sehingga dapat disimpulkan bahwa pola asuh orang tua responden memiliki hubungan dengan perkembangan sosial remaja di SMP Taruna Bhakti Depok. Menurut Joshi, Sharma, \& Mehra (2009) dan Rosli (2014), remaja dengan tipe pola asuh demokratif memiliki kestabilan emosi yang baik, kemampuan sosial, sikap mandiri, rasa empati yang positif, rasa percaya diri yang tinggi serta mudah beradaptasi dan diterima oleh lingkungan sosial.

Hal ini berhubungan erat dengan pola pengasuhan orang tua yang menampilkan sikap penerimaan dan pengawasan yang sangat baik sehingga remaja akan menampilkan perilaku yang positif pula (Milevsky, Schlechter, Netter, \& Keehn, 2008). Selain itu, remaja akan memiliki harga diri dan kepercayaan diri yang positif serta berani mengungkapkan pendapatnya kepada orang lain (Hockenberry, Marilyn, \& Wilson, 2015). Hal ini dipengaruhi oleh perilaku orang tua yang peka dan mampu memberikan arahan dan dukungan positif kepada remaja (Achtergarde, Postert, Wessing, Romer, \& Müller, 2015). Oleh karena itu, diharapkan agar perawat dapat bekerja sama dengan instansi terkait agar dapat meningkatkan 
peran orang tua dalam perkembangan sosial remaja sehingga remaja menjadi lebih siap dan matang dalam memasuki tahapan usia dewasa.

\section{Simpulan dan Saran}

Terdapat hubungan yang signifikan antara pola asuh orang tua dengan perkembangan sosial remaja di SMP Taruna Bhakti Depok, dimana remaja dengan pola asuh demokratif berpeluang lebih besar untuk memiliki perkembangan sosial kategori sesuai dibandingkan tipe pola asuh lainnya. Penelitian ini diharapkan dapat memberikan gambaran mengenai perkembangan sosial remaja, pola asuh orang tua, serta hubungan diantara keduanya kepada mahasiswa serta pelayanan dan profesi keperawatan dalam memberikan asuhan keperawatan yang komprehensif kepada remaja dan keluarga dalam praktiknya. Harapannya agar mahasiswa keperawatan dan perawat dapat menganalisa permasalahan sosial pada remaja serta memberikan informasi dan edukasi mengenai tugas perkembangan keluarga saat berpraktik dalam setting keluarga dan sekolah. Selain itu, penelitian ini diharapkan dapat meningkatkan kesadaran dan kerja sama antara instansi sekolah dengan orang tua terhadap pentingnya peran orang tua terhadap perkembangan sosial remaja dengan harapan dapat mencegah dan menurunkan kejadian permasalahan sosial remaja.

\section{Daftar Pustaka}

Abubakar, A., Van de Vijver, F. J., Suryani, A. O., Handayani, P., \& Pandia, W. S. (2015). Perceptions of parenting styles and their associations with mental health and life satisfaction among urban indonesian adolescents. Journal of Child and Family Studies , 24(9), 2680-2692.

doi:http://dx.doi.org/10.1007/s1082 6-014-0070-x.
Achtergarde, S., Postert, C., Wessing, I., Romer, G., \& Müller, J. M. (2015). Parenting and Child Mental Health Influences of Parent Personality, Child Temperament, and Their Interaction. The Family Journal , 23(2), 167-179.

Ball, J. (2012). Principles of Pediatric Nursing: Caring for Children 5th $E d$. New Jersey: Pearson Education, Inc.

Baumrind, D. (2005). Patterns of parental authority and adolescent autonomy. New directions for child and adolescent development, 2005(108), 61-69.

Bowden, V. R. (2010). Children and Their Families : The Continuum Of Care 2nd Ed. Philadelphia: Lippincott Williams \& Wilkins.

Boyd, D., \& Bee, H. (2006). Lifespan Development (4th ed.). New York: Pearson.

Christensen, \& Kockrow. (2011). Foundations and Adult Health Nursing 6th Edition. Canada: Elsevier.

Craig, G. J., \& Dunn, W. L. (2007). Understanding Human

Development. New Jersey: Pearson Prentice Hall.

Crone, E. A., \& Dahl, R. E. (2012). Understanding adolescence as a period of social-affective engagement and goal flexibility. Nature Reviews-Neuroscience, 13(9), 636-50. doi:http://dx.doi.org/10.1038/nrn33 13.

Daine, K., Hawton, K., Singaravelu, V., Stewart, A., Simkin, S., \& Montgomery, P. (2013). The power of the web: A systematic review of studies of the influence of the 
internet on self-harm and suicide in young people. 8 (10), p. e77555.

Desmita. (2010). Psikologi Perkembangan Peserta Didik. Bandung: PT. Remaja Rosdakarya.

Harris-Mckoy, D., \& Cui, M. (2013). Parental control, adolescent delinquency, and young adult criminal behavior. Journal of Child and Family Studies, 22(6), 836843.

Hendrian, D. (2017, Maret 6). Mengapa lebih 20 juta anak Indonesia mulai merokok sebelum 10 tahun? Komisi Perlindungan Anak Indonesia (KPAI) .

Hockenberry, Marilyn, J., \& Wilson, D. (2015). Wong's Nursing Care of Infants and Children 10th Ed. St Louis: Elsevier Inc.

Joshi, H. L., Sharma, M., \& Mehra, R. K. (2009). Depression among adolescents: Role of self efficacy and parenting style. Journal of Psychology \& Mental Health , 16, 13-17.

Kwon, K., Kim, E., \& Sheridan, S. M. (2012). A contextual approach to social skills assessment in the peer group: Who is the best judge? School Psychology Quarterly. , 27(3), 121.

Kyle, T., \& Carman, S. (2013). Essentials of Pediatric Nursing 2nd Edition. Philadelphia: Lippincott Williams \& Wilkins.

Madden, M., Lenhart, A., Cortesi, S., Gasser, U., Duggan, M., Smith, A., et al. (2013). Teens, social media, and privacy. Diambil kembali dari Teens, social media, and privacy

Malau, B. S. (2017, Januari 22). Gagalkan Aksi Tawuran, Polres Depok
Amankan 15 Remaja di Cimanggis. Warta Kota .

Milevsky, A., Schlechter, M., Netter, S., \& Keehn, D. (2008). Maternal and paternal parenting styles in adolescents: Associations with selfesteem, depression and lifesatisfaction. Journal of Children \& Family Studies , 16, 39-47.

Mitchell, R. N. (2006). Pocket Companion to Robbins \& Cotran Pathologic Basic of Disease 7th Ed. Singapore: Elsevier Inc.

Nurhayati, N. (2014). Profil Tugas Perkembangan Remaja Di SMK Negeri 1 Batudaa Kabupaten Gorontalo. Doctoral dissertation, Universitas Negeri Gorontalo .

Nurmanah, S. (2012). Hubungan pola asuh orang tua dengan perilaku merokok siswa SMA di SMA N 38 Jakarta. Skripsi. Fakultas Ilmu Keperawatan Universitas Indonesia

Pahur, R. A. (2008). Social skill differences between adolescent who percieved receiving Authoritative, Authoritarian, and Permissive parenting styles. Bachelor thesis. Faculty of Psychology, Atma Jaya Catholic University.

Radovic, A., Gmelin, T., Stein, B. D., \& Miller, E. (2016). Depressed adolescents' positive and negative use of social media. Journal of Adolescence, Volume 55, Pages 515.

Rosli, N. A. (2014). Effect of parenting styles on children's emotional and behavioral problems among different ethnicities of muslim children in the U.S (Order No. 3637178). Available from ProQuest Dissertations \& Theses Global. (1616761150). Retrieved from 
https://search.proquest.com/docvie $w / 1616761150$ ? accountid $=17242$.

Santrock, J. W. (2011). Life Span Development 13th Ed. New York: McGraw Hill.

Sebastian, C. L. (2015). Social cognition in adolescence: Social rejection and theory of mind. Psicología Educativa , 21(2), 125-131.

Simons-Morton, B. G., \& Farhat, T. (2010). Recent findings on peer group influences on adolescent smoking. The journal of primary prevention, 31(4), 191-208.

Ubertini, M. (2010). Cyberbullying may reduce adolescent's well-being: Can life satisfaction and social support protect them?(Order No. 3431797). Available from ProQuest Dissertations \& Theses Global. (808422604) , Retrieved from https://search.proquest.com/docvie w/808422604? accountid=17242. 